\title{
Solid-Contact Perchlorate Sensor with Nanomolar Detection Limit Based on Cobalt Phthalocyanine Ionophores Covalently Attached to Polyacrylamide
}

\author{
Mohammad Nooredeen Abbas ${ }^{\text {* }}$, Abdel Lattief A. Radwan", Philippe Bühlmann², \\ Mahmud A. Abd El Ghaffar ${ }^{3}$ \\ ${ }^{1}$ Analytical Laboratory, Department of Applied Organic Chemistry, National Research Centre, Cairo, Egypt \\ ${ }^{2}$ Department of Chemistry, University of Minnesota, Saint Paul, United States \\ ${ }^{3}$ Department of Polymers and Pigments, National Research Centre, Cairo, Egypt \\ E-mail: *dr.nooreldin@yahoo.com
}

Received July 29, 2011; revised September 3, 2011; accepted September 15, 2011

\begin{abstract}
Novel solid-contact perchlorate sensors based on cobalt phthalocyanine- $C$-monocarboxylic acid (I), and cobalt phthalocyanine- $C, C, C, C$-tetracarboxylic acid (II) as free ionophores and covalently attached to polyacrylamide (PAA) - ionophores III and IV, respectively were prepared. The all solid-state sensors were constructed by the application of a thin film of a polymer cocktail containing a phthalocyanine ionophore and cetyltrimethylammonium bromide (CTMAB) as a lipophilic cationic additive onto a gold electrode precoated with the conducting polymer poly (3,4-ethylenedioxythiophene) (PEDOT) as an ion and electron transducer. The sensor with $10.3 \%$ of ionophore (III) covalently attached to plasticizer-free poly (butyl methacrylate-co-dodecyl methacrylate) (PBDA) exhibited a good selectivity for perchlorate and discriminated many ions, including $\mathrm{F}^{-}, \mathrm{Cl}^{-}, \mathrm{Br}^{-}, \mathrm{I}^{-}, \mathrm{SCN}^{-}, \mathrm{NO}_{3}^{-}, \mathrm{S}^{2-}$ and $\mathrm{SO}_{4}^{2-}$. The covalent attachment of the ionophore to the polymer resulted in a near-Nernstian anionic slope of $-62.3 \mathrm{mV} /$ decade whereas a super-Nernstian slope of $-79.9 \mathrm{mV} /$ decade was obtained for the free ionophore. The sensor covered a linear concentration range of $5 \times 10^{-9}-1 \times$ $10^{-2} \mathrm{~mol} \cdot \mathrm{L}^{-1}$ with a lower detection limit (LDL) of $1 \times 10^{-9} \mathrm{~mol} \cdot \mathrm{L}^{-1}$ and gave a stable response over a $\mathrm{pH}$ range of $4-10.5$. The all-solid state sensors were utilized for the selective flow injection potentiometric determination of perchlorate in natural water and human urine samples in the nanomolar concentration range.
\end{abstract}

Keywords: Ion-Selective Electrode, Solid Contact, Covalent Ionophore Attachment, Perchlorate, Flow-Injection Analysis, Urine

\section{Introduction}

Perchlorate $\left(\mathrm{ClO}_{4}^{-}\right)$is an environmental contaminant whose occurrence is most clearly linked with its use as an oxidizer in rocket propellants, fireworks, matches, and highway safety flares [1]. Through accidental releases and improper disposal of materials containing its salts, perchlorate has entered the soil, surface water, and groundwater, and its solubility, mobility, and persistence characteristics have allowed it to contaminate drinking water. Perchlorate presents an environmental health risk to humans as it interferes with iodine uptake by the thyroid gland and is associated with the disruption of its function [2,3]. These reasons have stimulated research towards the accurate determination of perchlorate ions in different samples, such as urine and natural water [4-7]. Recently, chemical sensors have been used in many fields of applications, including clinical diagnosis, biomedical analysis and monitoring of environmentally hazardous materials [8-10]. The life span of these sensors and their lower limit of detection are among their most important characteristics. Therefore, increasing efforts are being directed towards the optimum design and operating conditions of long-living sensors. In particular, covalent binding of ionophores to polymeric sensing membranes provides long-term stability by preventing the ionophore from crystallizing, evaporating $[11,12]$ and leaching into sample solutions. In addition, it can improve the sensor 
selectivities and detection limits $[13,14]$. At the same time, all-solid-state ion-selective electrodes (ISEs) based on polymeric membranes doped with electrically neutral or charged ionophores (carriers) have attracted considerable interest since the invention of the so-called coated-wire electrode (CWE) more than 30 years ago [15]. Their further development led to ion-selective electrodes with a solid internal contact (SCISEs) $[16,17]$ characterized by a well-defined ion-to-electron transduction process between the ionically conducting ion-selective membrane and the electronically conducting substrate. The notable progress in sensor technology is manifested in the wide application of ion sensors in environmental analysis [18]. However, while there a considerable number of perchlorate ISEs were reported in the literature, most of them are not sensitive and selective enough to permit accurate measurements of the low levels of perchlorate usually encountered in real samples [19] and only have a limited lifetime. Therefore, the development of durable perchlorate sensor with improved sensitivity and selectivity is still an urgent need.

In this contribution, we report long-living highly selective and sensitive membrane electrodes for the determination of subnanomolar amounts of perchlorate in tap water, ground water and urine. We have utilized the combined use of covalent ionophore attachment and solid internal contacts for the preparation of these perchlorate selective electrodes. The construction and evaluation of perchlorate SCISEs based on cobalt phthalocyanine (Co-Pc) covalently attached to a polyacrylamide polymer backbone is described. As the ion-to-electron transducer, the conducting polymer poly (ethylenedioxy-thiophene) (PEDOT) was used. It was coated with either ionophore-doped plasticized poly (vinyl chloride) (PVC) or ionophore-doped plasticizer-free polymethacrylate membranes. At last, it is worthy to note that we have integrated the excellent potentiometric performance of the developed sensors with the agreed advantages of the flow injection technique with the high sample throughput and low sample volume.

\section{Experimental}

\subsection{Reagents and Materials}

All chemicals used were of analytical reagent grade unless stated otherwise, and doubly distilled water was used throughout. $o$-Nitrophenyl octyl ether (o-NPOE), bis (2-ethylhexyl) phthalate (DOP), dibutyl sebacate (DBS), dodecyl methacrylate and tetrahydrofuran (THF) were purchased from Sigma-Aldrich. Gold wires and conducting polymer dispersion in water composed of $0.5 \%$ poly (3,4-ethylene-dioxythiophene) with $0.8 \%$ poly (styrene sulfonate) (PEDOT/PSS) as dopant were pur- chased from Sigma-Aldrich. Sodium tetraphenylborate was obtained from Riedel de Haen, and oleic acid (OA) and high relative molecular weight PVC from Fluka. Tetrahydrofuran (THF), methyl methacrylate, n-butyl methacrylate and the sodium and potassium salts of all anions were purchased from Merck. Cetylpyridinium chloride (CPC) was purchased from ACROS, and dibutyl phthalate (DBP) and cetyltrimethylammonium bromide (CTMAB) from BDH.

A stock solution of $0.1 \mathrm{~mol} \cdot \mathrm{L}^{-1}$ potassium perchlorate was prepared in water, and 8 working standards in the range from $10^{-2} \mathrm{~mol} \cdot \mathrm{L}^{-1}$ to $10^{-9} \mathrm{~mol} \cdot \mathrm{L}^{-1}$ (each differing from the next more concentrated standard by a factor of 10) were freshly prepared by stepwise dilution. Phosphate buffer $\left(0.1 \mathrm{~mol} \cdot \mathrm{L}^{-1}\right)$ of $\mathrm{pH} 7.2$ was used to adjust the $\mathrm{pH}$ of all sample solutions.

\subsection{Instrumentation}

All pH measurements were made at $25 \pm 1^{\circ} \mathrm{C}$ using a pH/Ion meter Model 692 (Metrohm). A PC-based EMF16 high-resolution data logger (Lawson) was used to record the output signals. A combination $\mathrm{pH}$ glass electrode Model Metrohm 6.0202.100 was used for all pH measurements, and a Metrohm double junction $\mathrm{Ag} / \mathrm{AgCl}$ reference electrode Model 6.0726.100 containing 3 $\mathrm{mol} \cdot \mathrm{L}^{-1} \mathrm{KCl}$ solution in the outer compartment and 3 $\mathrm{mol} \cdot \mathrm{L}^{-1} \mathrm{KCl}$ solution saturated with $\mathrm{AgCl}$ in the inner compartment was used for all other potentiometric measurements. Standard solutions were freshly prepared with doubly distilled water.

\subsection{Synthesis of Ionophores}

The ionophores cobalt phthalocyanine- $C$-monocarboxylic acid (I) and cobalt phthalocyanine-C,C,C,C-tetracarbox ylic acid (II) and the adducts of phthalocyanine- $C$-mono carboxylic acid-PAA (III) and cobalt phthalocyanineC,C,C,C-tetracarboxylic acid-PAA (IV), were synthesized according to the Figure 1 and characterized by elemental analysis and UV-Vis and IR spectroscopy. In brief, condensation of trimellitic anhydride in the presence of urea, ammonium molybdate and cobalt acetate was used to form the tetraformamido-phthalocyanine cobalt. By hydrolyzing the product in alkaline medium, ionophore II was obtained. The synthesis of ionophore I was carried out according to a procedure described by Chen et al. [20]. By heating a mixture of trimellitic anhydride and phthalic anhydride at a ratio of $1: 7$ to $190^{\circ} \mathrm{C}$ in the presence of urea, cobalt acetate, and ammonium molybdate, a mixture of cobalt 2-formamido-phthalocyanine and cobalt phthalocyanine was obtained. The cobalt formamido-phthalocyanine thus prepared was hydrolyzed under 


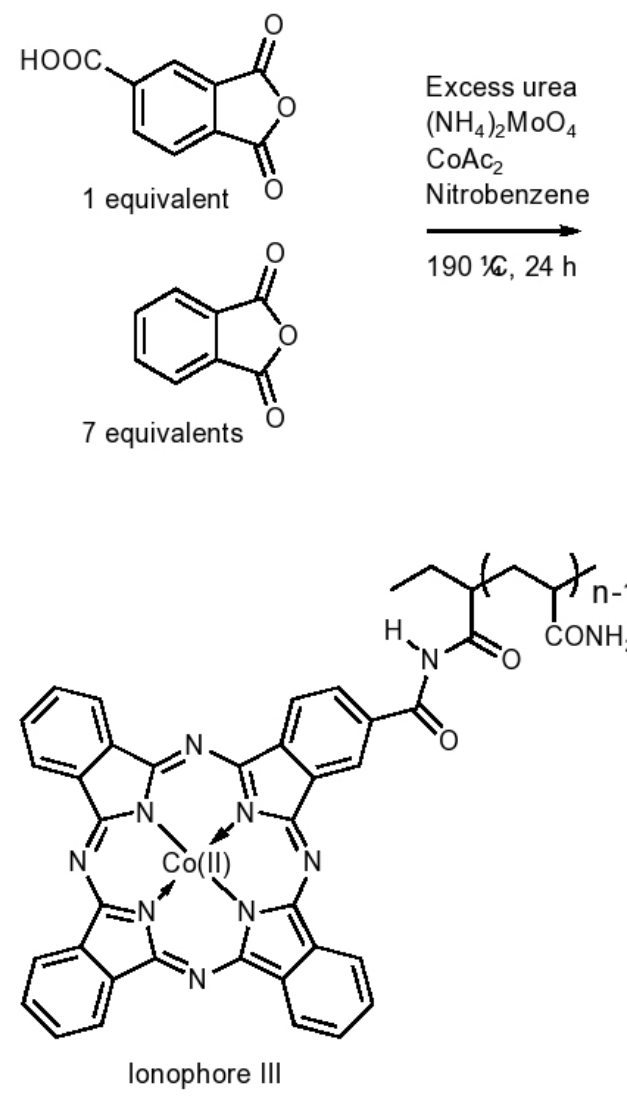

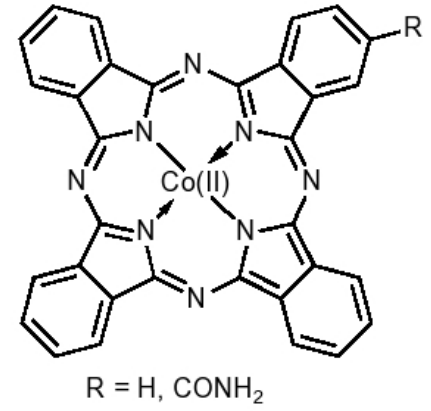

$$
=\mathrm{H}, \mathrm{CONH}_{2}
$$$$
\begin{aligned}
& 1 \mathrm{M} \mathrm{KOH} \\
& 901 / 4,16 \mathrm{~h}
\end{aligned}
$$

Ionophore I: $\mathrm{R}=\mathrm{COOH}$

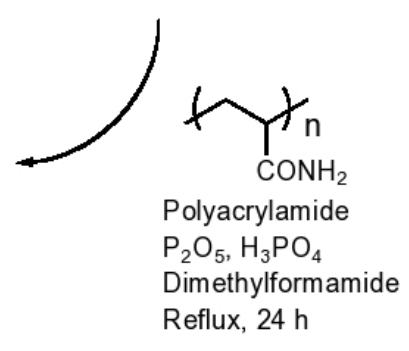

Figure 1. Synthesis of the free ionophore cobalt phthalocyanine monocarboxylic acid (I) and the ionophore III, covalently attached to polyacrylamide.

alkaline condition, yielding ionophore I. The latter was isolated from the hydrolysis mixture by separation of the carboxy derivative from the cobalt phthalocyanine and the remaining formamido derivative on a silica gel column, eluting with a dimethyl formamide:acetone mixture $(3: 1)$. While the formamido-substituted and the unsubstituted phthalocyanine eluted as a leading band, ionophore I was more strongly retained and eluted as a well-separated second band.

The ionophore-polymer adducts were synthesized by condensation of the carboxylic group of ionophores I and II with the $\mathrm{NH}_{2}$ groups of PAA by refluxing in dimethyl formamide at $150^{\circ} \mathrm{C}$ in the presence of polyphosphoric acid, adopting a previously reported procedure [21,22]. In the IR spectrum of compound I, the peaks at 1577 , $1461,1299,1036$ and $719 \mathrm{~cm}^{-1}$ are those characteristic of the phthalocyanine ring. The existence of a carboxylic group on the phthalocyanine ring of I was confirmed by the peaks at $1726 \mathrm{~cm}^{-1}$ and $1664 \mathrm{~cm}^{-1}(\mathrm{C}=\mathrm{O}$ stretching $)$ and $3199 \mathrm{~cm}^{-1}$ (OH stretching). In the spectrum of the PAA-attached ionophore (compound III), the peaks at 3435 (N-H), 2926 (C-H), 1634 (amide II, NH), and 1404 $\mathrm{cm}^{-1}(\mathrm{C}-\mathrm{N})$ belong to the polyacrylamide backbone. The characteristic phthalocyanine peaks at 1268, 1079 and
$635 \mathrm{~cm}^{-1}$ were still present. The peak at $1726 \mathrm{~cm}^{-1}$ and $3199 \mathrm{~cm}^{-1}$ disappeared, indicating reaction of the $\mathrm{COOH}$ with the NH group from the PAA. The UV spectrum of the cobalt phthalocyanine- $C$-monocarboxylic acid showed a Q band at $661 \mathrm{~nm}$ and a higher B band at $296 \mathrm{~nm}$, while the spectrum of the polymer-attached ionophore (III) showed a weaker satellite band at $661 \mathrm{~nm}$ with a shift of the B band to $328 \mathrm{~nm}$, which is in agreement with results of Chen et al. [23].

\subsection{Preparation of Coated Graphite Electrodes (CGEs)}

The proper amounts of the specified ionophore (I, II, III or IV), PVC and the plasticizer (DOP, DBP, o-NPOE, or DBS) were placed in a $10 \mathrm{~mL}$ vial and mixed thoroughly. Additives such as oleic acid and/or cetyltrimethylammonium bromide (CTMAB) were added (see Results and Discussion). Then the mixture was dissolved in $5 \mathrm{~mL}$ THF under magnetic stirring until the thus prepared membrane cocktail became clear. Some membranes were prepared using the plasticizer-free copolymer of butyl methacrylate and dodecyl methacrylate (PBDA) instead of PVC and plasticizer. A clean and dry carbon rod of $4 \mathrm{~cm}$ length 
and $2 \mathrm{~mm}$ diameter was dipped to about $1 \mathrm{~cm}$ depth into the membrane cocktail for $2 \mathrm{~s}$, and then lifted out of the solution to evaporate the THF, leaving the polymeric membrane layer coating the carbon rod. That operation was repeated for 12 - 17 times to give a proper membrane thickness. The rod was fitted into a plastic body and connected with the membrane-free end to the $\mathrm{pH} /$ ion meter using a copper wire.

\subsection{Preparation of Solid-Contact Electrodes (SCEs) with Gold Contacts}

Gold wire (1 cm length and $0.1 \mathrm{~mm}$ diameter) was carefully washed with $1 \mathrm{~mol} \cdot \mathrm{L}^{-1} \mathrm{H}_{2} \mathrm{SO}_{4}$, water and acetone, dried, and attached to a silver wire using conducting silver-epoxy glue (silver epoxy E10-101, Alfa). The conducting polymer films were cast from an aqueous dispersion of PEDOT/PSS containing of $\mathrm{FeCl}_{3}$ onto $\mathrm{Au}$ wire. The thus obtained polymer films possess low water solubility and allowed for stabilized standard electrode potential [24]. Finally, the membrane cocktail was applied onto the dry PEDOT/PSS polymer layer deposited onto the gold electrode. The electrodes were conditioned in a $1 \times 10^{-2} \mathrm{~mol} \cdot \mathrm{L}^{-1}$ perchlorate solution for at least $48 \mathrm{~h}$ before their first use and kept in such a solution overnight when not in use. Figure 2 shows a schematic drawing of the all-solid contact sensor.

\subsection{ISE Calibration}

The ISEs were calibrated by immersion, along with an $\mathrm{Ag} / \mathrm{AgCl} / \mathrm{Cl}^{-}$reference electrode, in a $50-\mathrm{mL}$ beaker containing $9.0 \mathrm{~mL}$ phosphate buffer solution $\left(0.1 \mathrm{~mol} \cdot \mathrm{L}^{-1}\right)$ of $\mathrm{pH}$ 7.2. Then aliquots of a standard perchlorate solution were added successively under continuous stirring to obtain solutions with a perchlorate concentration ranging from $1 \times 10^{-10}$ to $1 \times 10^{-1} \mathrm{~mol} \cdot \mathrm{L}^{-1}$, and the potential was recorded after stabilization to $\pm 0.5 \mathrm{mV}$ within approximately $1 \mathrm{~min}$. A calibration graph was then constructed by plotting the recorded potentials as a function of the logarithm of the perchlorate concentration.

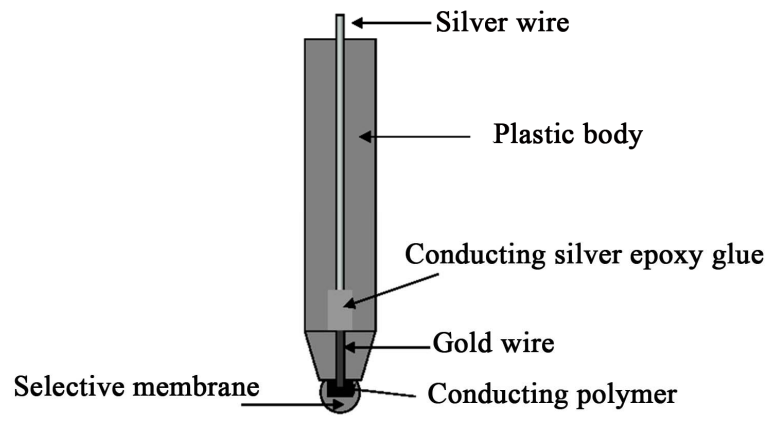

Figure 2. Schematic of the solid contact electrode (SCE).

\subsection{Sensor Selectivity}

Potentiometric selectivity coefficients $K_{A, B}^{\text {pot }}$ were determined according to IUPAC guidelines using the separate solutions method (SSM) [25,26]. Different interfering anions of a concentration of $1 \times 10^{-3} \mathrm{~mol} \cdot \mathrm{L}^{-1}$ in phosphate buffer ( $\left.\mathrm{pH} 7.2,0.1 \mathrm{~mol} \cdot \mathrm{L}^{-1}\right)$ were utilized, and selectivity coefficients were obtained using Equation (1).

$$
\log K_{A, B}^{p o t}=\frac{E_{B}-E_{A}}{S}+\left(1-\frac{Z_{A}}{Z_{B}}\right) \log C_{A}
$$

where $S$ is the slope of the calibration curve, $c_{A}$ the concentration of perchlorate, and $z_{A}$ and $z_{B}$ are the charges of perchlorate and the interfering anion, respectively.

\subsection{Flow Injection Analysis}

Test solutions were injected using an injection valve Model 5060 (Rheodyne). The carrier buffer solution was propelled by means of a four channel peristaltic pump model MCP (Ismatec) through Tygon tubing R3603 of $0.25 \mathrm{~mm}$ i.d. The all-solid state perchlorate selective electrodes along with $\mathrm{Ag} / \mathrm{AgCl} / \mathrm{Cl}^{-}$double junction reference electrodes were used to detect perchlorate in a home-built micro-flow cell of $250 \mathrm{uL}$ volume. Figure 3 shows a schematic diagram for the flow injection set-up.

\section{Results and Discussions}

\subsection{Effect of Ionophores Type, Plasticizer, and Ionic Sites on Response Slope and Detection Limit}

Phthalocyanines and metal phthalocyanines are well-known, readily available pigments that have good chemical, acid-base, and thermal stabilities. They represent one of the most studied classes of organic functional materials [26-28]. In particular, they have been successfully used as ionophores for potentiometric sensing, which takes advantage of their selective coordination chemistry and structural diversity [29,30]. The type of phthalocyanine ring, the nature of their peripheral substituents, and the choice of the central metal control the axial ligation of different anions to these compounds [31,32]. We attached the phthalocyanine ionophores I and II covalently to polyacrylamide (PAA) through the condensation reaction between the carboxyl groups of the ionophores I and II and the $\mathrm{NH}_{2}$ groups of PAA, giving ionophores III and $\mathrm{IV}$, respectively. The four compounds were investigated as anion sensing ionophores, and preliminary results showed a strong response towards perchlorate. 


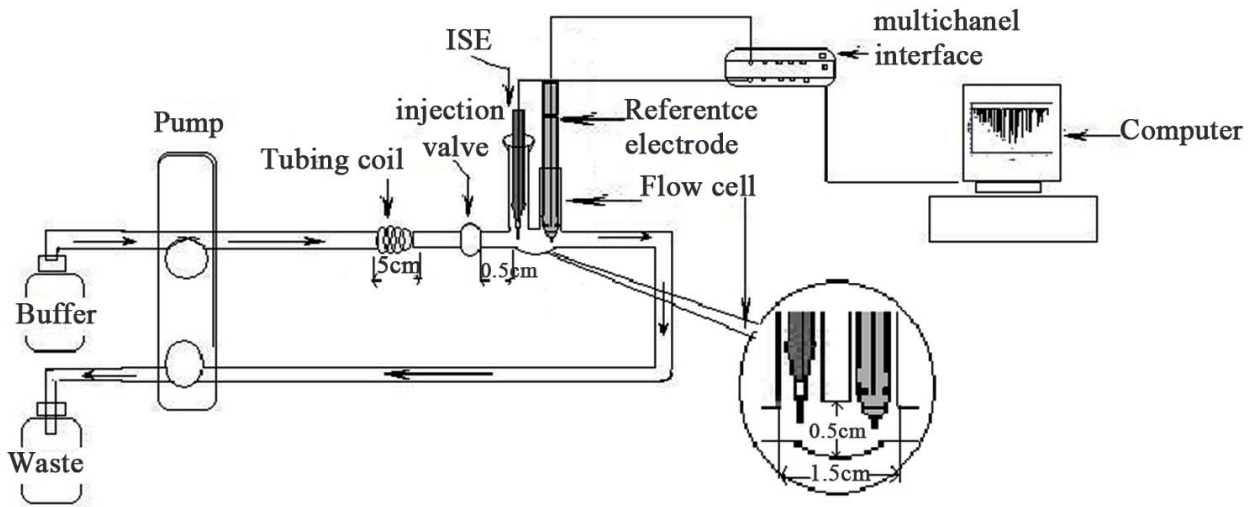

Figure 3. Schematic diagram for flow injection system for perchlorate-selective sensor.

UV-VIS spectra of $10^{-4} \mathrm{~mol} \cdot \mathrm{L}^{-1}$ cobalt phthalocyanine monocarboxylic acid in DMSO/water (1:1) in presence and absence of $10^{-4} \mathrm{~mol} \cdot \mathrm{L}^{-1}$ perchlorate are shown in Figure 4. As previously shown for other Co(II) phthalocyanines [33], axial ligation of anions leads to a very significant increase in the intensities of the Q band at 661 $\mathrm{nm}$ as well as the smaller bands at 294 and $328 \mathrm{~nm}$. Moreover, there is a small shift in the band at $250 \mathrm{~nm}$. All this is consistent with perchlorate binding to the metal centre of the ionophore.

It is well known that the potentiometric sensitivity and selectivity of a given ionophore depends significantly on the membrane composition [34-36]. For preliminary experiments, a number of coated graphite electrodes (CGEs) with PVC membranes containing no ionophore or different concentrations of ionophores I, II, III or IV were prepared, and their potentiometric response to perchlorate in phosphate buffer of $\mathrm{pH} 7.2$ was evaluated. All membranes contained DOP as plasticizer, 2.6\% CTMAB to provide for ionic sites, and $2.6 \%$ oleic acid as additional additive. Blank electrodes without ionophores showed no response at all. Membranes containing no added ionic

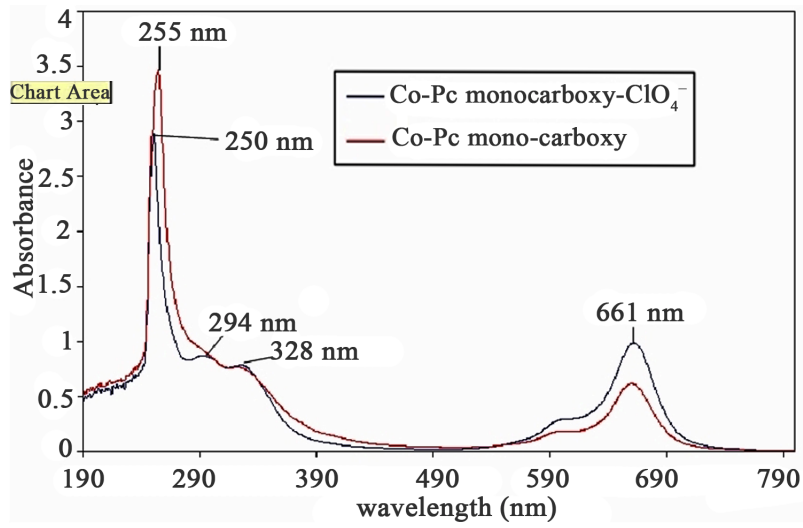

Figure 4. UV-VIS spectra of $10^{-4} \mathrm{~mol} \cdot \mathrm{L}^{-1}$ cobalt phthalocyanine monocarboxylic acid in 1:1 DMSO/water in presence and absence of $10^{-4} \mathrm{~mol} \cdot \mathrm{L}^{-1}$ potassium perchlorate. sites but $3.86 \%$ of ionophore I, which is the cobalt phthalocyanine- $C$-monocarboxylic acid not attached to the polymer, showed a super-Nernstian slope of about -120 $\mathrm{mV} /$ decade in the range of $1 \times 10^{-4}$ to $1 \times 10^{-5} \mathrm{~mol} \cdot \mathrm{L}^{-1}$ (see Figure 5). Ionophore IV was less soluble in the membrane cocktail than III, with a maximum concentration of $5.5 \%$, which is about half as much as for III. This may be related to the formation of a cross-linked polymer as a result of the reaction of more than one carboxylic group, while ionophore III was attached to the poly- mer through only one carboxylic acid group. At a ratio of $3.86 \%$, ionophore IV gave a slightly better detection limit than ionophore III. On the other hand, it was possible to increase the ratio of ionophore III in the membrane up to $10.3 \%$, where a lower detection limit than for the other three ionophores were achieved.

Preliminary studies using CGEs to test the effect of the plasticizer type, ionic sites and oleic acid were also

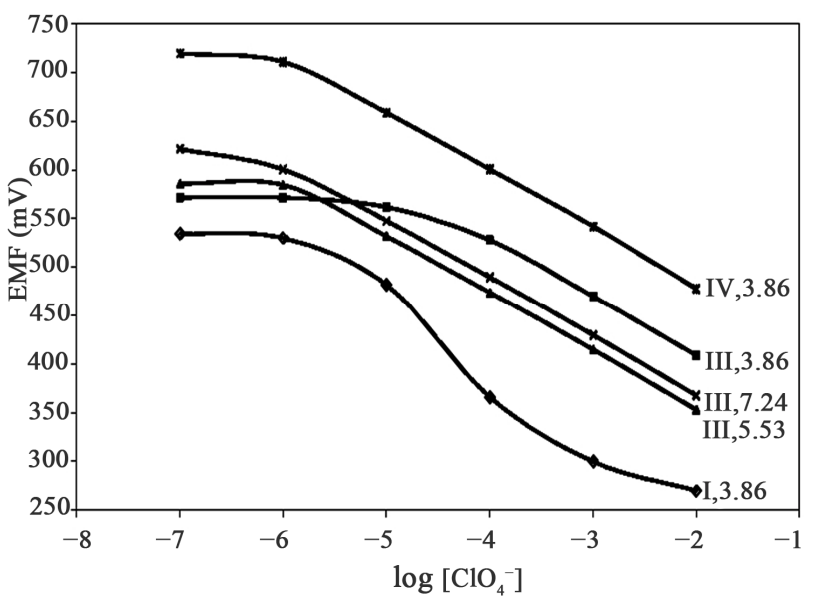

Figure 5. Effect of the type of and concentration of ionophore (in \%, wt/wt) on the perchlorate response of coatedgraphite electrodes using ionophores I, III or IV. All membranes contained PVC, were plasticized with DOP, and contained $2.6 \%$ CTMAB and $2.6 \% \mathrm{OA}$ in addition to the ionophore. 
Table 1. Effect of membrane composition on the potentiometric response of all solid-contact perchlorate sensors.

\begin{tabular}{ccccccc}
\hline No. & Composition \% & A\# M.R. & OA M.R. & Slope mV/d & LDL M & Linear Range M \\
\hline 1 & No ionophore, No PAA, PBDA 100 & - & - & - & - & - \\
2 & No ionophore, PAA 9.3, PBDA 85.5 & $2.6^{*}$ & $2.6^{*}$ & -32.7 & $2 \times 10^{-5}$ & $8 \times 10^{-5}-1 \times 10^{-2}$ \\
3 & I 2.52, PAA 6.78, PBDA 85.5 & 0.48 & 0.38 & -79.94 & $2 \times 10^{-6}$ & $7 \times 10^{-6}-1 \times 10^{-2}$ \\
4 & III 7.24, PBDA 87.6 & 0.82 & 0.64 & -61.7 & $8 \times 10^{-8}$ & $2 \times 10^{-7}-1 \times 10^{-2}$ \\
5 & III 8.3, PBDA 86.5 & 0.71 & 0.56 & -61.9 & $1 \times 10^{-8}$ & $8 \times 10^{-8}-1 \times 10^{-2}$ \\
6 & III 9.3, PBDA 85.5 & 0.64 & 0.50 & -62.3 & $2 \times 10^{-9}$ & $6 \times 10^{-9}-1 \times 10^{-2}$ \\
7 & III 10.3, PBDA 84.5 & 0.57 & 0.45 & -63.9 & $1 \times 10^{-9}$ & $5 \times 10^{-9}-1 \times 10^{-2}$ \\
8 & III 10.3, PVC 28.2, DOP 56.4 & 0.57 & 0.45 & -63.4 & $1.5 \times 10^{-9}$ & $6 \times 10^{-9}-1 \times 10^{-2}$ \\
\hline
\end{tabular}

-A\# = CTMAB-M.R. $=$ molar ratio of additive/ionophore. ${ }^{*}$ The membrane contains $2.6 \% \mathrm{w} / \mathrm{w} \mathrm{CTMAB}+2.6 \% \mathrm{w} / \mathrm{w} \mathrm{OA}$, and doesn't contain ionophore.

performed. It is well known that the nature and concentration of the membrane plasticizer influences both the dielectric constant of the membrane as well as the mobility of ions. Among the plasticizers used in this work (oNPOE, DBP, DOS, DBS and DOP), DOP gave potentiometric slopes closest to the theoretically expected values. Therefore, DOP was used as the plasticizer for all further studies.

The presence of lipophilic cations as ionic sites in ISE membranes selective for monoanions diminishes the ohmic resistance of ISE membranes doped with ionophores, and the ratio of ionic sites and ionophore can be used to control the selectivity $[37,38]$. Moreover, in the case of electrically neutral ionophores, cationic sites are a necessity for the observation of Nernstian responses. Indeed, better response characteristics, i.e., Nernstian responses and lower detection limits were observed when incorporating an optimum amount of CTMAB in the membrane of the perchlorate-selective electrode, which in agreement with recent reports [39-41]. Moreover, the detection limits of the electrodes were slightly improved in the presence of a small amount of oleic acid (OA), a result that resembles previous results for anion-selective electrodes $[42,43]$ and may be related to an improvement in ionophore solubility due to the presence of OA.

\subsection{Solid Contact Electrodes with Gold Contacts}

We subsequently applied the optimized membrane composition for the fabrication of solid contact electrodes with gold contacts (SCE-Au). PEDOT is known as one of the most stable conducting polymers available today and particularly suitable as a solid contact material for SCISEs due to its low sensitivity to $\mathrm{O}_{2}$ and $\mathrm{CO}_{2}$ [44]. The conducting polymer films were prepared by casting of an aqueous dispersion of PEDOT/PSS onto the gold electrodes. The crosslinked conducting polymer films has a water solubility and hence stabilize the standard potential of the sensors [45]. The produced layers of conducting polymer were then coated with a film of plasti- cizer-free PBDA copolymer, either with or without cobalt phthalocyanine ionophore.

The absence of an aqueous layer between the solidcontact and ion-sensitive membrane was confirmed using the method proposed by Fibbioli et al. [46]. The electrodes were exposed first to samples containing a high concentration of the interfering ion chlorate, and the potential was then monitored as the sample was changed to a solution of the primary ion perchlorate. The presence of an aqueous layer would be indicated by a slow positive potential drift after changing from the interfering to the primary ion, resulting from ion exchange between the sample and the aqueous layer. However, the obtained results show that there is no such potential drift, indicating the absence of an aqueous layer between the solid contact and the ion-selective membrane.

Table 1 shows that blank sensors without ionophores did not result in any response to perchlorate, and sensors containing PAA without ionophore exhibited a response with a low slope of $-32.7 \mathrm{mV} /$ decade (electrode \#2). Membrane sensors with $2.52 \%$ of ionophore I (not attached to the polymer) showed a super-Nernstian response with a slope of $-79.9 \mathrm{mV} /$ decade (\#3) (see Figure 5). Only the sensor with a membrane containing $2.6 \%$ CTMAB, 2.6\% OA, and 10.3\% of ionophore III (\#7) i.e. attached ionophore, showed a near-Nernstian slope of $-63.9 \mathrm{mV} / \mathrm{decade}$. Its linear range covered the range from $5 \times 10^{-9}$ to $1 \times 10^{-2} \mathrm{~mol} \cdot \mathrm{L}^{-1}$ and gave a lower detection limit of (LDL) of $1 \times 10^{-9} \mathrm{~mol} \cdot \mathrm{L}^{-1}$, as shown in Figure 6 .

Electrodes with membranes with an otherwise identical composition but prepared with DOP-plasticized PVC as membrane matrix $(\# 8)$ exhibited a slope of -63.4 $\mathrm{mV} /$ decade, a linear range of $8 \times 10^{-9}-1 \times 10^{-2}$ $\mathrm{mol} \cdot \mathrm{L}^{-1}$ and a LDL of $4 \times 10^{-9}$, which is rather similar to that of the plasticizer-free PBDA membranes, the former being only slightly better.

\subsection{Elimination of the Super-Nernstian Response}

Potentiometric responses to monanions with response 


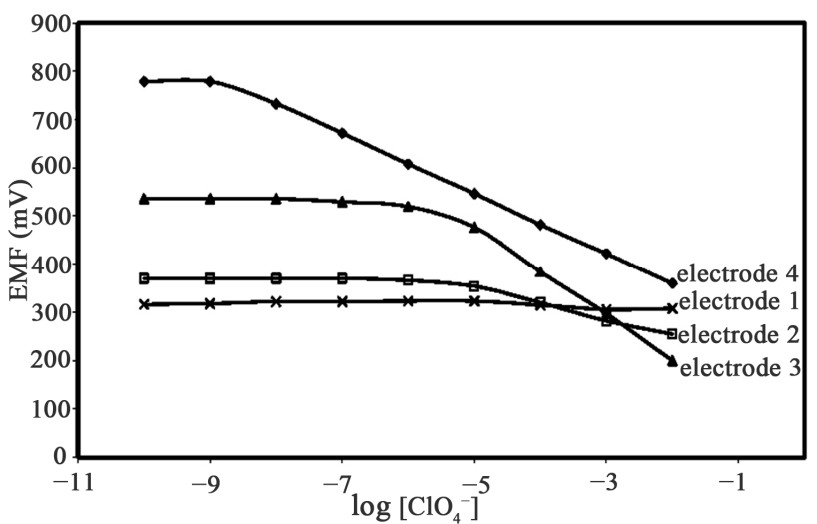

Figure 6. Potentiometric response of perchlorate SCISEs: Electrode 1 : 100\% BDA (blank 1). Electrode 2: 9.3\% PAA, 85.5\% BDA (blank 2). Electrode 3: $2.5 \%$ ionophore I, 6.78\% PAA, 85.5\% BDA. Electrode 4: 9.3\% ionophore III, $85.5 \%$ BDA. Electrode membranes 2 to 4 also all contained $2.6 \% \mathrm{OA}$ and $2.6 \%$ CTMAB.

slopes larger than $-59 \mathrm{mV} /$ decade were observed previously and could be explained in one case with a thermodynamic model by the formation of hydroxide-bridged metalloporphyrin ionophore dimers. Indeed, the covalent attachment of the ionophore to a polymer backbone was shown to prevent ionophore dimerization and eliminated the super Nernstian response $[47,48]$. This makes it noteworthy that in the present work an increasing ratio of the covalently attached cobalt phthalocyanine in the polymer matrix started to slightly increase the potentiometric slope of the sensor again at the highest concentration of ionophore, as can be seen in Table 1. Because the electrodes were always conditioned in a $1 \times 10^{-2} \mathrm{~mol} \cdot \mathrm{L}^{-1}$ perchlorate solution before use and stored in the same type of solution overnight, it appears that here too a thermodynamic explanation may explain this finding. The higher ionophore concentrations may permit dimerization of the ionophore despite the covalent ionophore attachment to the polymer.

\subsection{Effect of PH Value}

The effect of the $\mathrm{pH}$ on the potential of the perchlorate electrodes with ionophores III and IV was examined in the range of perchlorate concentrations from $1 \times 10^{-5}$ to 1 $\times 10^{-1} \mathrm{~mol} \cdot \mathrm{L}^{-1}$. The $\mathrm{pH}$ was varied by adding $\mathrm{HCl}$ or $\mathrm{NaOH}$. For ionophore IV and all four concentrations assayed, the electrode potential was independent of $\mathrm{pH}$ in a range of $\mathrm{pH} 6-11$. The potentiometric response was also independent on $\mathrm{pH}$ from 4 to 10.5 for ionophore III for all five perchlorate concentrations assayed. The potential changes observed outside of this $\mathrm{pH}$ range are likely due to the response of the electrode to $\mathrm{OH}^{-}(\mathrm{pH}>$ $10)$ and to chloride ions $(\mathrm{pH}<4)$. It is concluded that the perchlorate selective all solid-state sensor possesses a very stable response over a wide $\mathrm{pH}$ range. A $\mathrm{pH}$ of 7.2 adjusted with $0.1 \mathrm{~mol} \cdot \mathrm{L}^{-1}$ phosphate buffer was used for all further studies.

\subsection{Potentiometric Selectivity}

Potentiometric selectivity coefficients of the proposed sensors for several anions relative to perchlorate were determined with the separate solution method (SSM). It is clear from Table 2 that the electrode possesses good selectivity for perchlorate over all other studied anions and that there is a notable improvement in selectivity by using covalently attached ionophore (III). The observed selectivity pattern for the proposed sensor is in the sequence of $\mathrm{ClO}_{4}^{-}>\mathrm{IO}_{3}^{-}>\mathrm{BrO}_{3}^{-}>\mathrm{I}^{-}>\mathrm{SCN}^{-}>\mathrm{F}^{-}>$ $\mathrm{Br}^{-}>\mathrm{Cl}^{-}>\mathrm{NO}_{2}^{-}>\mathrm{NO}_{3}^{-}>\mathrm{CH}_{3} \mathrm{COO}^{-}>\mathrm{SO}_{4}^{2-}>\mathrm{S}^{2-}$ $>\mathrm{CO}_{3}^{2-}>\mathrm{PO}_{4}^{3-}$, which shows a deviation from the

Table 2. Selectivity of the perchlorate SCISE's.

\begin{tabular}{|c|c|c|c|}
\hline $\begin{array}{l}\text { Interfering } \\
\text { ion }\end{array}$ & & chlorate SCISE, & $\operatorname{og} K_{A, B}^{p o t}$ \\
\hline & $\begin{array}{c}\text { Free } \\
\text { Ionophore I, } \\
9.3 \%\end{array}$ & $\begin{array}{c}\text { Free Ionophore } \\
\text { I, }{ }^{*} 1.86 \%+ \\
7.44 \% \text { PAA }\end{array}$ & $\begin{array}{c}\text { Attached Ionophore } \\
\text { III, } 9.3 \%=(1.86 \% \\
\text { Co-Pc })\end{array}$ \\
\hline $\mathrm{ClO}_{3}^{-}$ & -1.08 & -1.13 & -1.35 \\
\hline $\mathrm{IO}_{3}^{-}$ & -1.12 & -1.46 & -1.57 \\
\hline $\mathrm{BrO}_{3}^{-}$ & -1.21 & -1.44 & -1.81 \\
\hline $\mathrm{I}^{-}$ & -1.39 & -1.85 & -2.01 \\
\hline $\mathrm{SCN}^{-}$ & -1.10 & -1.32 & -2.33 \\
\hline $\mathrm{F}^{-}$ & -2.83 & -2.87 & -2.50 \\
\hline $\mathrm{Br}^{-}$ & -2.11 & -2.64 & -2.52 \\
\hline $\mathrm{Cl}^{-}$ & -2.31 & -2.75 & -2.70 \\
\hline $\mathrm{NO}_{2}^{-}$ & -2.12 & -2.24 & -2.85 \\
\hline $\mathrm{NO}_{3}^{-}$ & -2.87 & -2.82 & -2.99 \\
\hline $\mathrm{CH}_{3} \mathrm{COO}^{-}$ & -3.01 & -3.02 & -2.99 \\
\hline $\mathrm{SO}_{4}^{2-}$ & -2.67 & -2.75 & -3.05 \\
\hline $\mathrm{S}^{-2}$ & -1.25 & -1.77 & -3.14 \\
\hline $\mathrm{CO}_{3}^{2-}$ & -3.48 & -3.01 & -3.55 \\
\hline $\mathrm{PO}_{4}^{3-}$ & -3.78 & -3.80 & -3.90 \\
\hline $\mathrm{H}_{2} \mathrm{PO}_{4}^{-}$ & -3.88 & -3.92 & -3.94 \\
\hline $\mathrm{HPO}_{4}^{2-}$ & -3.91 & -3.95 & -3.98 \\
\hline
\end{tabular}

*The amount of ionophore I and PAA is equivalent to those present in ionophore III-All membranes contains $2.6 \% \mathrm{w} / \mathrm{w}$ CTMAB $+2.6 \% \mathrm{w} / \mathrm{w}$ OA III was stable for at least 90 days to $\pm 0.5 \mathrm{mV}$; longer experiments were not performed. 
Table 3. Comparison between the potentiometric performance and the selectivity of the proposed electrode and those for previously reported perchlorate-selective electrodes.

\begin{tabular}{|c|c|c|c|c|}
\hline Interfering ion $K_{\mathrm{ClO}_{4}, \mathrm{~B}}^{\text {pot. }} \geq \mathbf{1 . 0} \times \mathbf{1 0}^{-\mathbf{2}}$ & LDL (M) & Linear range (M) & Slope $\mathrm{mV} /$ decade & Ref. \\
\hline $\mathrm{ClO}_{3}^{-}, \mathrm{IO}_{3}^{-}, \mathrm{BrO}_{3}^{-}$ & $1.0 \times 10^{-9}$ & $5.0 \times 10^{-9}-1.0 \times 10^{-2}$ & -62.3 & This work \\
\hline $\mathrm{IO}_{4}^{-}, \mathrm{SCN}^{-}, \mathrm{I}^{-}, \quad \mathrm{NO}_{3}^{-}$ & $5.6 \times 10^{-7}$ & $8.0 \times 10^{-7}-1.0 \times 10^{-1}$ & -60.3 & 15 \\
\hline $\begin{array}{c}\mathrm{C}_{2} \mathrm{O}_{4}^{2-}, \mathrm{HCO}_{3}^{-}, \mathrm{SO}_{4}^{2-}, \mathrm{SO}_{3}^{2-}, \mathrm{BrO}_{3}^{-}, \mathrm{NO}_{2}^{-}, \mathrm{F}^{-}, \mathrm{Cl}^{-}, \\
\mathrm{Cr}_{2} \mathrm{O}_{7}^{2-}\end{array}$ & $6.6 \times 10^{-7}$ & $1.0 \times 10^{-6}-1.0 \times 10^{-1}$ & -60.0 & 50 \\
\hline $\mathrm{CO}_{3}^{2-}, \mathrm{SO}_{4}^{2-}, \mathrm{NO}_{2}^{-}, \mathrm{C}_{2} \mathrm{O}_{4}^{2-}, \mathrm{Cl}^{-}, \mathrm{SCN}^{-}$ & $8.3 \times 10^{-7}$ & $1.0 \times 10^{-6}-1.0 \times 10^{-1}$ & -56.8 & 51 \\
\hline $\mathrm{SCN}^{-}, \mathrm{Br}^{-}, \mathrm{CN}^{-}, \mathrm{ClO}_{3}^{-}, \mathrm{CO}_{3}^{2-}, \mathrm{NO}_{3}^{-}, \mathrm{C}_{2} \mathrm{O}_{4}^{2-}, \mathrm{CrO}_{4}^{2-}, \mathrm{I}^{-}$ & $8 \times 10^{-7}$ & $1.0 \times 10^{-6}-1.0 \times 10^{-1}$ & -60.6 & 52 \\
\hline $\mathrm{SO}_{4}^{2-}, \mathrm{Cl}^{-}, \mathrm{HCO}_{3}^{-}, \mathrm{Br}^{-}, \mathrm{NO}_{3}^{-}, \mathrm{CH}_{3} \mathrm{COO}^{-}, \mathrm{C}_{2} \mathrm{O}_{4}^{2-}, \mathrm{HPO}_{4}^{2-}$ & $9.3 \times 10^{-6}$ & $5.2 \times 10^{-6}-1.0 \times 10^{-1}$ & $-51.3-55.7$ & 53 \\
\hline $\mathrm{MnO}_{4}^{-}$ & $2 \times 10^{-7}$ & $5.0 \times 10^{-7}-1.0 \times 10^{-1}$ & -59.3 & 54 \\
\hline $\mathrm{Cl}^{-}, \mathrm{SCN}^{-}, \mathrm{Br}^{-}, \mathrm{SO}_{4}^{2-}, \mathrm{NO}_{3}^{-}, \mathrm{NO}_{2}^{-}, \mathrm{F}^{-}, \mathrm{CN}^{-}$ & $5 \times 10^{-6}$ & $8 \times 10^{-6}-1.6 \times 10^{-1}$ & -57.8 & 55 \\
\hline $\mathrm{SO}_{4}^{2-}, \mathrm{SO}_{3}^{2-}, \mathrm{Cl}^{-}, \mathrm{F}^{-}, \mathrm{HCO}_{3}^{-}, \mathrm{Br}^{-}, \mathrm{NO}_{3}^{-}, \mathrm{ClO}_{3}^{-}$ & $5.6 \times 10^{-6}$ & $1.0 \times 10^{-5}-1.0 \times 10^{-2}$ & -48.3 & 56 \\
\hline $\begin{array}{c}\mathrm{CO}_{3}^{2-}, \mathrm{SO}_{4}^{2-}, \mathrm{SO}_{3}^{2-}, \mathrm{BrO}_{3}^{-}, \mathrm{I}^{-}, \mathrm{Br}^{-}, \mathrm{ClO}_{3}^{-}, \mathrm{Cl}^{-}, \\
\mathrm{HCO}_{3}^{-}, \mathrm{NO}_{3}^{-}\end{array}$ & $1.1 \times 10^{-6}$ & $5.0 \times 10^{-6}-1.0 \times 10^{-2}$ & -57 & 57 \\
\hline $\mathrm{SCN}^{-}, \mathrm{CO}_{3}^{2-}, \mathrm{I}^{-}$ & $5.0 \times 10^{-6}$ & $1.0 \times 10^{-5}-1.0 \times 10^{-2}$ & -59 & 58 \\
\hline
\end{tabular}

hydrophobicity-based Hofmeister series: $\mathrm{ClO}_{4}^{-}>\mathrm{SCN}^{-}$ $>\mathrm{I}^{-}>\mathrm{CN}^{-}>\mathrm{ClO}_{3}^{-}>\mathrm{NO}_{3}^{-}>\mathrm{Br}^{-}>\mathrm{BrO}_{3}^{-}>\mathrm{Cl}^{-}>\mathrm{F}^{-}$ (i.e., the series based solely on lipophilicity of anions) [49]. The selectivities of the proposed sensor along with other performance characteristics are shown in Table 3 along with data for some previously reported perchlorate-selective electrodes for comparison.

\subsection{Response Time and Life Span}

Calibrations were carried out by immersing the sensors in a $1 \times 10^{-2} \mathrm{~mol} \cdot \mathrm{L}^{-1}$ perchlorate solution buffered with phosphate to a $\mathrm{pH}$ of 7.2, followed by serial dilution. Carrying out the calibration in a reverse way from low to high concentrations resulted always in the same potentiometric slope. The sensor was typically kept in $1 \times 10^{-2} \mathrm{~mol} \cdot \mathrm{L}^{-1}$ phosphate buffered perchlorate solution of $\mathrm{pH} 7.2$ before use in the next experiment. However, it was stored dry when not in use for a long time. The response slope of the sensor constructed using ionophore III was almost stable over a period of 90 days and it is expected to retain its characteristics over longer living time. The response time of the sensor was found to be $\sim 12 \mathrm{~s}$ over concentration range from 10-7 to 10-2 M. which is reliably fast .

\subsection{Optimization of the Parameters of FIP Method}

Flow injection analysis with potentiometric detection using ISEs has many advantages, including low cost, simple instrumentation, rapid response, high selectivity and sensitivity $[59,60]$. The high reproducibility, low detection limit and need for only a small sample for analysis are now well-recognized features of this technique. Moreover, the high sample throughput is an appreciated advantage of flow injection potentiometry (FIP). Therefore, the proposed miniaturized all-solid-state perchlorate-sensor and a tubular flow cell with phosphate buffer as carrier was utilized for FIP determinations of perchlorate. The parameters of the FIP method were optimized in order to obtain the best signal sensitivity and sampling rate under low dispersion conditions. The geometry of the homebuilt flow-cell allowed for limited sample dispersion and, thereby, for optimum sensitivity and fast response of the sensor. A sample volume of 500 $\mu \mathrm{L}$ and a flow rate of $30 \mathrm{~mL} / \mathrm{min}$ were found to offer the best results. Under optimum conditions, the residence time $\mathrm{T}$ was $10-15 \mathrm{~s}$ (where $\mathrm{T}$ is the time span from injection to the appearance of maximum signal), the travel time $\mathrm{t}$ was $5-6 \mathrm{~s}$ (where $\mathrm{t}$ is the period elapsing from injection to the start of the signal), the return time $T$ ' was $30-40 \mathrm{~s}$ (where $\mathrm{T}^{\prime}$ is the period between the appearance of the maximum signal and the return to the base line), and the baseline-to-baseline time $\Delta \mathrm{T}$ was 50 - $60 \mathrm{~s}$ (where $\Delta \mathrm{T}$ is the interval between the start of the signal and its return to the baseline). The results prove that the proposed sensor exhibited a very fast response toward perchlorate, allowing a sampling rate of about 60 samples per hour at least. Figure 7 shows triplicate peaks from the proposed 


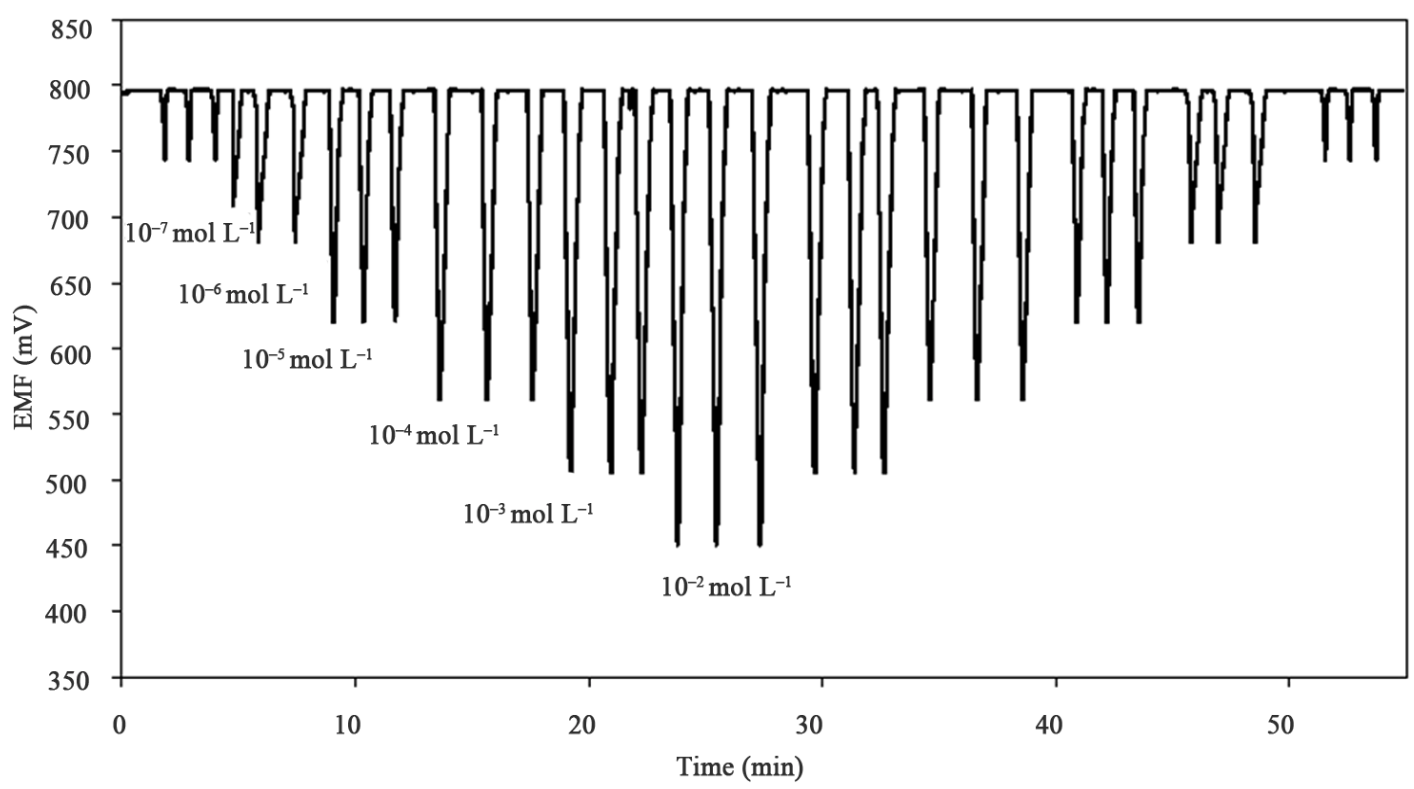

Figure 7. Responses of the FIP system obtained under optimized experimental conditions for triplicate injections of $\mathrm{ClO}_{4}^{-}$in the range of $1.0 \times 10^{-7}$ to $1.0 \times 10^{-2} \mathrm{~mol} \cdot \mathrm{L}^{-1}$.

FIP system obtained under optimal experimental conditions for varying concentrations of $\mathrm{ClO}_{4}^{-}$in the range of $1.0 \times 10^{-7}$ to $1.0 \times 10^{-2} \mathrm{~mol} \cdot \mathrm{L}^{-1}$.

\subsection{Analytical Applications}

We utilized the new sensor for the determination of perchlorate in water and human urine samples. Mineral water, tap water and human urine samples were spiked with various concentrations of perchlorate, and the $\mathrm{pH}$ of the sample solutions was adjusted to $\mathrm{pH} 7.2$ using phosphate buffer solution, before the samples were analyzed by direct and flow injection analysis using the all solidcontact electrodes. As Table 4 shows, quantitative recovery was achieved for samples spiked with perchlorate in a concentration as low as $10 \mathrm{pbb}$.

\section{Conclusions}

An all-solid-state perchlorate sensor based on cobalt monocarboxyphthalocyanine covalently attached to a polyacrylamide backbone was successfully prepared. The covalent attachment of the ionophore to the polymer was crucial for improving the characteristic performance of the sensor, resulting in a Nernstian potentiometric response by inhibiting dimerization of the free ionophore molecules. Additionally, the sensor containing the attached ionophore exhibited good selectivity for perchlorate. Finally, the combination of the developed perchlorate SCISE with FIA method allowed for FIP analysis of
Table 4. Determination of perchlorate anions in tap water, ground water and human urine by direct and flow injection potentiometric analysis using the proposed all solid-state electrode.

\begin{tabular}{cccc}
\hline Sample & $\begin{array}{c}\text { Perchlorate } \\
\text { added }(\mu \mathrm{g} / \mathrm{ml})\end{array}$ & DP R*, \% & FIP R*, \% \\
\hline Bottled water & 5.00 & $99.9 \pm 0.3$ & $99.1 \pm 0.2$ \\
& 0.50 & $97.9 \pm 0.2$ & $97.9 \pm 0.4$ \\
& 0.01 & $92.9 \pm 0.6$ & $92.7 \pm 0.5$ \\
Tap water & 5.00 & $99.7 \pm 0.1$ & $97.8 \pm 0.3$ \\
& 0.50 & $95.6 \pm 0.2$ & $94.9 \pm 0.1$ \\
& 0.01 & $93.1 \pm 0.2$ & $92.6 \pm 0.2$ \\
Urine & 5.00 & $98.1 \pm 0.3$ & $96.8 \pm 0.2$ \\
& 0.50 & $92.7 \pm 0.4$ & $92.0 \pm 0.5$ \\
& 0.01 & $89.4 \pm 0.6$ & $88.8 \pm 0.5$ \\
\hline
\end{tabular}

$\mathrm{DP}=$ direct potentiometry, FIP = flow injection potentiometry. ${ }^{*}$ Recovery, mean of five determinations.

the hazardous perchlorate ion at very low concentrations, with the known advantages of the FIA method of low sample volume and high throughput.

\section{Acknowledgements}

This work was supported by the Office of International Science and Engineering (OISE) of the National Science Foundation (Project 0809328). 


\section{References}

[1] P. E. Jackson, S. Gokhale, T. Streib, J. S. Rohrer and C. A. Pohl, "Improved Method for the Determination of Trace Perchlorate in Ground and Drinking Waters by Ion Chromatography," Journal of Chromatography A, Vol. 888, No. 1-2, 2000, pp. 151-158. doi:10.1016/S0021-9673(00)00557-4

[2] K. O. Yu, L. Narayanan, D. R. Mattie, R. J. Godfrey, P. N. Todd, T. R. Sterner, D. A. Mahle, M. N. Lumpkin and J. W. Fisher, "The Pharmacokinetics of Perchlorate and Its Effect on the Hypothalamus-Pituitary-Thyroid Axis in the Male Rat," Toxicology and Applied Pharmacology, Vol. 182, No. 2, 2002, pp. 148-159. doi:10.1006/taap.2002.9432

[3] R. A. Clewell, E. A. Merrill, K. O. Yu, D. A. Mahle, T. R. Sterner, D. R. Mattie, P. J. Robinson, J. W. Fisher and J. M. Gearhart, "Predicting Neonatal Perchlorate Dose and Inhibition of Iodide Uptake in the Rat during Lactation Using Physiologically-Based Pharmacokinetic Modeling," Toxicological Sciences, Vol. 74, No. 2, 2003, pp. 416-436. doi:10.1093/toxsci $/ \mathrm{kfg} 147$

[4] B. Rezaei, S. Meghdadi and S. Bagherpour, "PerchlorateSelective Polymeric Membrane Electrode Based on Bis (Dibenzoylmethanato) Cobalt(II) Complex as a Neutral Carrier," Journal of Hazardous Materials, Vol. 161, No. 2-3, 2009, pp. 641-648. doi:10.1016/j.jhazmat.2008.04.005

[5] A. Soleymanpour, B. Garaili and S. M. Nabavizadeh, "Perchlorate Selective Membrane Electrodes Based on a Platinum Complex," Monatshefte fur Chemie, Vol. 139, No. 12, 2008, pp. 1439-1445. doi:10.1007/s00706-008-0947-8

[6] M. R. Ganjali, P. Norouzi, F. Faridbod, M. Yousefi, L. Naji and M. Salavati-Niasari, "Perchlorate-Selective Membrane Sensors Based on Two Nickel-Hexaaza-macrocycle Complexes," Sensors and Actuators B: Chemical, Vol. 120, No. 2, 2007, pp. 494-499. doi:10.1016/j.snb.2006.03.002

[7] M. Arvand, A. Pourhabib, R. Shemshadi and M. Giahi, "The Potentiometric Behavior of Polymer-Supported Metallophthalocyanines Used as Anion-Selective Electrodes," Analytical and Bioanalytical Chemistry, Vol. 387, No. 3, 2007, pp. 1033-1039.

doi:10.1007/s00216-006-0988-y

[8] E. Pretsch, "The New Wave of Ion-Selective Electrodes," Trends in Analytical Chemistry, Vol. 26, No. 1, 2007, pp. 46-51. doi:10.1016/j.trac.2006.10.006

[9] E. Bakker and E. Pretsch, "Potentiometric Sensors for Trace-Level Analysis," Trends in Analytical Chemistry, Vol. 24, No. 3, 2005, pp. 199-207. doi:10.1016/j.trac.2005.01.003

[10] A. Michalska and K. Maksymiuk, "All-Plastic, Disposable, Low Detection Limit Ion-Selective Electrodes," Analytica Chimica Acta, Vol. 523, No. 1, 2004, pp. 97105. doi:10.1016/j.aca.2004.07.020
[11] S. Daunert and L. G. Bachas, "Ion-Selective Electrodes Using an Ionophore Covalently Attached to Carboxylated poly (Vinyl Chloride)," Analytical Chemistry, Vol. 62, No. 14, 1990, pp. 1428-1431. doi:10.1021/ac00213a016

[12] R. Bereczki, R. E. Gyurcsányi, B. Ágai and K. Tóth, "Synthesis and Characterization of Covalently Immobilized Bis-Crown Ether Based Potassium Ionophore," Analyst, Vol. 130, No. 1, 2005, pp. 63-70. doi:10.1039/b410410b

[13] Y. Qin, S. Peper, A. Radu, A. Ceresa and E. Bakker, "Plasticizer-Free Polymer Containing a Covalently Immobilized $\mathrm{Ca}^{2+}$-Selective Ionophore for Potentiometric and Optical Sensors," Analytical Chemistry, Vol. 75, No. 13, 2003, pp. 3038-3045. doi:10.1021/ac0263059

[14] M. Püntener, T. Vigassy, E. Baier, A. Ceresa and E. Pretsch, "Improving the Lower Detection Limit of Potentiometric Sensors by Covalently Binding the Ionophore to a Polymer Backbone," Analytica Chimica Acta, Vol. 503, No. 2, 2004, pp. 187-194. doi:10.1016/j.aca.2003.10.030

[15] R. W. Cattrall and H. Freiser, "Coated Wire Ion Selective Electrodes,” Analytical Chemistry, Vol. 43, No. 13, 1971, pp. 1905-1906. doi:10.1021/ac60307a032

[16] B. P. Nikolskii and E. A. Materova, "Solid Contact in Membrane Ion-Selective Electrodes," Ion-Selective Electrode Reviews, Vol. 7, No. 1, 1985, pp. 3-39.

[17] E. Lindner and R. E. Gyurcsányi, "Quality Control Criteria for Solid-Contact, Solvent Polymeric Membrane Ion-Selective Electrodes," Journal of Solid State Electrochemistry, Vol. 13, No. 1, 2009, pp. 51-68. doi:10.1007/s10008-008-0608-1

[18] R. De Marco, G. Clarke and B. Pejcic, "Ion-Selective Electrode Potentiometry in Environmental Analysis," Electroanalysis, Vol. 19, No. 19-20, 2007, pp. 1987-2001. doi:10.1002/elan.200703916

[19] Interim Drinking Water Health Advisory for Perchlorate, "Health and Ecological Criteria Division," Office of Science and Technology, Office of Water U.S. EPA, Washington D.C., December 2008.

[20] J. Chen, N. Chen, J. Huang, J. Wang and M. Huang, "Derivatizable Phthalocyanine with Single Carboxyl Group: Synthesis and Purification," Inorganic Chemistry Communications, Vol. 9, No. 3, 2006, pp. 313-315. doi:10.1016/j.inoche.2005.12.002

[21] M. A. Abd El-Ghaffar, N. R. El-Halawany and H. A. Essawy, "Phthalocyanine/Laponite Nanocomposites as Multifunction Additives for Stabilization of Polymeric Materials," Journal of Applied Polymer Science, Vol. 108, No. 5, 2008, pp. 3225-3232. doi:10.1002/app.27558

[22] H. A. Essawy, N. A. Abd El-Wahab and M. A. Abd El-Ghaffar, "PVC-Laponite Nanocomposites: Enhanced Resistance to UV Radiation," Polymer Degradation and Stability, Vol. 93, No. 8, 2008, pp. 1472-1478. doi:10.1016/j.polymdegradstab.2008.05.015

[23] W. Chen, B. Zhao, Y. Pan, Y. Yao, S. Lu, S. Chen and L. Du, "Preparation of a Thermosensitive Cobalt Phthalo- 
cyanine/N-Isopropylacrylamide Copolymer and Its Catalytic Activity on Thiol," Journal of Colloid and Interface Science, Vol. 300, No. 2, 2006, pp. 626-632. doi:10.1016/j.jcis.2006.04.008

[24] M. Vázquez, P. Danielsson, J. Bobacka, A. Lewenstam and A. Ivaska, "Solution-Cast Films of Poly(3,4-Ethylene-Dioxythiophene) as Ion-to-Electron Transducers in All-Solid-State Ion-Selective Electrodes," Sensors and Actuators B: Chemical, Vol. 97, No. 2-3, 2004, pp. 182189. doi:10.1016/j.snb.2003.08.010

[25] E. Lindner and Y. Umezawa, "Performance Evaluation Criteria for Preparation and Measurement of Macro- and Microfabricated Ion-Selective Electrodes (IUPAC Technical Report)," Pure and Applied Chemistry, Vol. 80, No. 1, 2008, pp. 85-104. doi:10.1351/pac200880010085

[26] Y. umezawa, P. Bühlmann, K. Umezawa, K. Tohda and S. Amemiya, "Potentiometric Selectivity Coefficients of Ion-Selective Electrodes Part I. Inorganic Cations (Technical Report)," Pure and Applied Chemistry, Vol. 72, No. 10, 2000, pp. 1851-2082. doi:10.1351/pac200072101851

[27] N. B. McKeown, "Phthalocyanine Materials: Synthesis, Structure and Function," Cambridge University Press, Cambridge, 1998.

[28] N. B. McKeown, "Out of the Blue," Chemistry and Industry (London), No. 3, 1999, pp. 92-98.

[29] W. Xu, R. Yuan, Y. Chai, T. Zhang, W. Liang and X. Wu, "Fabrication of an Iodide-Selective Electrode Based on Phthalocyaninatotitanium(IV) Oxide and the Selective Determination of Iodide in Actual Samples," Analytical and Bioanalytical Chemistry, Vol. 392, 2008, pp. 297303. doi:10.1007/s00216-008-2243-1

[30] J. Liu, Y. Masuda and E. Sekido, "Response Properties of an Ion-Selective Polymeric Membrane Phosphate ElecTrode Prepared with Cobalt Phthalocyanine and Characterization of the Electrode Process," Journal of Electroanalytical Chemistry, Vol. 291, No. 1-2, 1990, pp. 67-79. doi:10.1016/0022-0728(90)87178-M

[31] J. Li, X. Wu, R. Yuan, H. Lin and R. Yu, "Cobalt Phthalocyanine Derivatives as Neutral Carriers for Nitrite-Sensitive Poly (Vinyl Chloride) Membrane Electrodes," Analyst, Vol. 119, 1994, pp. 1363-1366. doi:10.1039/an9941901363

[32] S. Shahrokhian, M. Amini, S. Kolagar and S. Tangestaninejad, "Coated-Graphite Electrode Based on Poly (Vinyl Chloride)-Aluminum Phthalocyanine Membrane for Determination of Salicylate," Microchemical Journal, Vol. 63, No. 2, 1999, pp. 302-310. doi:10.1006/mchj.1999.1794

[33] T. Nakamura, C. Hayashi and T. Ogawara, "Potentiometric Response Properties of Sensor Membranes Based on Cobalt Phthalocyanine Conjugate-Polymer in Nonaqueous Solutions," Bulletin of the Chemical Society of Japan, Vol. 69, No. 6, 1996, pp. 1555-1559. doi:10.1246/bcsj.69.1555

[34] V. V. Egorov and A. A. Bolotin, "Ion-Selective Electrodes for Determination of Organic Ammonium Ions:
Ways for Selectivity Control," Talanta, Vol. 70, No. 5, 2006, pp. 1107-1116.

doi:10.1016/j.talanta.2006.02.025

[35] E. Bakker, "Generalized Selectivity Description for PolyMeric Ion-Selective Electrodes Based on the Phase Bound-Ary Potential Model," Journal of Electroanalytical Chemistry, Vol. 639, No. 1-2, 2010, pp. 1-7. doi:10.1016/j.jelechem.2009.09.031

[36] U. Schaller, E. Bakker and U. Spichiger, "Nitrite-Selec tive Microelectrodes," Talanta, Vol. 41, No. 6, 1994, pp. 1001-1005. doi:10.1016/0039-9140(94)E0048-V

[37] P. M. Gehrig, W. E. Morf, M. Welti, E. Pretsch and W. Simon, "Catalysis of Ion Transfer by Tetraphenylborates in Neutral Carrier-Based Ion-Selective Electrodes," Helvetica Chimica Acta, Vol. 73, No. 1, 1990, pp. 203-212. doi:10.1002/hlca.19900730124

[38] E. Bakker, E. Malinowska, R. D. Schiller and M. E. Meyerhoff, "Anion-Selective Membrane Electrodes Based on Metalloporphyrins: The Influence of Lipophilic Anionic and Cationic Sites on Potentiometric Selectivity," Talanta, Vol. 41, No. 6, 1994, pp. 881-890. doi:10.1016/0039-9140(94)E0041-O

[39] V. K. Gupta, R. N. Goyal and R. A. Sharma, "Anion Recognition Using Newly Synthesized Hydrogen Bonding Disubstituted Phenylhydrazone-Based Receptors: Poly (Vi-Nyl Chloride)-Based Sensor for Acetate," Talanta, Vol. 76, No. 4, 2008, pp. 859-864. doi:10.1016/j.talanta.2008.04.046

[40] W. Zhou, Y. Chai, R, Yuan, X. Wu and J. Guo, "Potentiometric Iodide Selectivity of Polymer-Membrane Sensors Based on Co(II) Triazole Derivative," Electroanalysis, Vol. 20, No. 13, 2008, pp. 1434-1439. doi:10.1002/elan.200704197

[41] M. A. Zanjanchi, M. Arvand, M. Akbari, K. Tabatabaeian and G. Zaraei, "Perchlorate-Selective Polymeric MemBrane Electrode Based on a cobaloxime as a Suitable Carrier," Sensors and Actuators B: Chemical, Vol. 113, No. 1, 2006, pp. 304-309. doi:10.1016/j.snb.2005.03.003

[42] S. Sadeghi, A. Gafarzade, M. A. Naseri and H. Shargi, "Triiodide-Selective Polymeric Membrane Electrodes Based on Schiff Base Complexes of Cu (II) and Fe (III)," Sensors and Actuators B: Chemical, Vol. 98, No. 2-3, 2004, pp. 174-179. doi:10.1016/j.snb.2003.10.005

[43] M. Shamsipur, M. Yousefi, M. R. Ganjali, T. Poursaberi and M. Faal-Rastgar, "Highly Selective Sulfate PVC-Membrane Electrode Based on 2,5-Diphenyl-1,2,4,5-Tetraaza-bicyclo[2.2.1 Heptane as a Neutral Carrier," Sensors and Actuators B: Chemical, Vol. 82, No. 1, 2002, pp. 105 -110. doi:10.1016/S0925-4005(01)00997-2

[44] M. Vázquez, J. Bobacka, A. Ivaska and A. Lewenstam, "Influence of Oxygen and Carbon Dioxide on the Electrochemical Stability of Poly(3,4-Ethylene Dioxy Thiophene) Used as Ion-to-Electron Transducer in All-SolidState Ion-Selective Electrodes," Sensors and Actuators B: Chemical, Vol. 82, No. 1, 2002, pp. 7-13. 
[45] M. Vázquez, P. Danielsson, J. Bobacka, A. Lewenstam and A. Ivaska, "Solution-Cast Films of Poly(3,4-Ethylene-dioxythiophene) as Ion-to-Electron Transducers in All-Solid-State Ion-Selective Electrodes," Sensors and Actuators B: Chemical, Vol. 97, No. 2-3, 2004, pp. 182189. doi:10.1016/j.snb.2003.08.010

[46] M. Fibbioli, W. E. Morf, M. Badertscher, N. F. de Rooij and E. pretsch, "Potential Drifts of Solid-Contacted IonSelective Electrodes Due to Zero-Current Ion Fluxes through the Sensor Membrane," Electroanalysis, Vol. 12, No. 16, 2000, pp. 1286-1292. doi:10.1002/1521-4109(200011)12:16<1286::AID-ELAN 1286>3.0.CO;2-Q

[47] E. Steinle, S. Amemiya, P. Buhlmann and M. Meyerhoff, "Origin of Non-Nernstian Anion Response Slopes of Metalloporphyrin-Based Liquid/Polymer Membrane Electrodes," Analytical Chemistry, Vol. 72, No. 23, 2000, pp. 5766-5773. doi:10.1021/ac000643x

[48] J. Casabó, L. Escriche, C. Pérez-Jiménez, J. A. Munoz, F. Teixidor, J. Bausells and A. Errachid, "Application of a New Phosphadithiamacrocycle to $\mathrm{ClO}_{4}^{-}$-Selective CHEMFET and Ion-Selective Electrode Devices," Analytica Chimica Acta, Vol. 320, No. 1, 1996, pp. 63-68. doi:10.1016/0003-2670(95)00526-9

[49] Y. Marcus, "Thermodynamic Functions of Transfer of Single Ions from Water to Nonaqueous and Mixed Solvents: Part I-Gibbs Free Energies of Transfer to Nonaqueous Solvents," Pure and Applied Chemistry, Vol. 55, No. 6, 1983, pp. 977-1021. doi:10.1351/pac198355060977

[50] B. Rezaei, S. Meghdadi and V. Nafisi, "Fast Response and Selective Perchlorate Polymeric Membrane Electrode Based on Bis(Dibenzoylmethanato) Nickel(II) Complex as a Neutral Carrier," Sensors and Actuators B: Chemical, Vol. 121, No. 2, 2007, pp. 600-605. doi:10.1016/j.snb.2006.04.093

[51] M. A. Zanjanchi, M. Arvand, M. Akbari, K. Tabatabaeian and G. Zaraei, "Perchlorate-Selective Polymeric Membrane Electrode Based on a Cobaloxime as a Suitable Carrier," Sensors and Actuators B: Chemical, Vol. 113, No. 1, 2006, pp. 304-309. doi:10.1016/j.snb.2006.04.093

[52] M. M. Ardakani, M. Jalayer, H. Naeimi and H. R. Zare, "Perchlorate-Selective Membrane Electrode Based on a New Complex of Uranil," Analytical and Bioanalytical
Chemistry, Vol. 381, No. 6, 2005, pp. 1186-1192. doi:10.1007/s00216-004-3011-5

[53] J. Lizondo-Sabater, M. J. Segui, J. M. Lloris, R. MartínezMañez, T. Pardo, F. Sancenón and J. Soto, "New Membrane Perchlorate-Selective Electrodes Containing Polyazacycloalkanes as Carriers," Sensors and Actuators B: Chemical, Vol. 101, No. 1-2, 2004, pp. 20- 27. doi:10.1016/j.snb.2004.02.018

[54] M. R. Ganjali, M. Yousefi, T. Poursaberi, L. Naji, M. Salavati-Niasari and M. Shamsipur, "Highly Selective and Sensitive Perchlorate Sensors Based on Some Recently Synthesized Ni(II)-Hexaazacyclotetradecane Complexes," Electroanalysis, Vol. 15, No. 18, 2003, pp. 1476 -1480._doi:10.1002/elan.200302679

[55] M. Shamsipur, A. Soleymanpour, M. Akhond, H. Sharghi and A. R. Hasaninejad, "Perchlorate Selective Membrane Electrodes Based on a Phosphorus(V)-Tetraphenylporphyrin Complex," Sensors and Actuators B: Chemical, Vol. 89, No. 1-2, 2003, pp. 9-14. doi:10.1016/S0925-4005(02)00401-X

[56] C. Sanchez-Pedreño, J. A. Ortuño and J. Hernández, "Flow Injection Potentiometry of Primary and Interfering Ion with a Gold Complex Ion-Exchange Membrane," Talanta, Vol. 55, No. 1, 2001, pp. 201-207. doi:10.1016/S0039-9140(01)00418-0

[57] C. Sanchez-Pedreño, J. A. Ortuño and J. Hernández, "Perchlorate-Selective Polymeric Membrane Electrode Based on a Gold (I) Complex: Application to Water and Urine Analysis," Analytica Chimica Acta, Vol. 415, No. 1-2, 2000, pp. 159-164. doi:10.1016/S0003-2670(00)00872-2

[58] T. A. Bendikov and T. C. Harmon, "Long-Lived Solid State Perchlorate Ion Selective Sensor Based on Doped Poly(3,4-Ethylenedioxythiophene) (PEDOT) Films," Analytica Chimica Acta, Vol. 551, No. 1-2, 2005, pp. 30-36. doi:10.1016/j.aca.2005.07.004

[59] J. Ruzicka and E. H. Hansen, "Flow Injection Analysis," 2nd Edition, Wiley, New York, 1988.

[60] P. W. Alexander, T. Dimitrakopoulos and D. B. Hibbert, "A Six Sensor Array of Coated-Wire Electrodes for Use in a Portable Flow Injection Analyzer," Electroanalysis, Vol. 10, No. 10, 1998, pp. 707-712. doi:10.1002/(SICI)1521-4109(199808)10:10<707::AID-E LAN707>3.0.CO;2-V 